\title{
Synthesis and Effect of the Structure of Bithienyl-Terminated Surfactants for Dielectric Layer Modification in Organic Transistor
}

\author{
Lucia Feriancová $^{1}\left(\mathbb{D}\right.$, Iveta Kmentová ${ }^{1}$, Michal Micjan ${ }^{2}$, Milan Pavúk ${ }^{3}$, Martin Weis ${ }^{2, *(D)}$ and Martin Putala ${ }^{1, *(D)}$ \\ 1 Department of Organic Chemistry, Faculty of Natural Sciences, Comenius University in Bratislava, \\ Ilkovičova 6, 84215 Bratislava, Slovakia; feriancova13@uniba.sk (L.F.); iveta.kmentova@uniba.sk (I.K.) \\ 2 Institute of Electronics and Photonics, Slovak University of Technology, Ilkovičova 3, \\ 81219 Bratislava, Slovakia; michal.micjan@stuba.sk \\ 3 Institute of Nuclear and Physical Engineering, Slovak University of Technology, Ilkovičova 3, \\ 81219 Bratislava, Slovakia; milan.pavuk@stuba.sk \\ * Correspondence: martin.weis@stuba.sk (M.W.); martin.putala@uniba.sk (M.P.); Tel.: +421-910942310 (M.W.); \\ +421-2-90149323 (M.P.)
}

check for

updates

Citation: Feriancová, L.; Kmentová, I.; Micjan, M.; Pavúk, M.; Weis, M.; Putala, M. Synthesis and Effect of the Structure of Bithienyl-Terminated Surfactants for Dielectric Layer Modification in Organic Transistor. Materials 2021, 14, 6345. https:// doi.org/10.3390/ma14216345

Academic Editor:

Arunas Ramanavicius

Received: 29 September 2021

Accepted: 21 October 2021

Published: 23 October 2021

Publisher's Note: MDPI stays neutral with regard to jurisdictional claims in published maps and institutional affiliations.

Copyright: (c) 2021 by the authors. Licensee MDPI, Basel, Switzerland. This article is an open access article distributed under the terms and conditions of the Creative Commons Attribution (CC BY) license (https:/ / creativecommons.org/licenses/by/ $4.0 /)$.

\begin{abstract}
A series of bithienyl-terminated surfactants with various alkyl chain lengths (from C8 to C13) and phosphono or chlorodimethylsilyl anchoring groups were synthesized by palladiumcatalyzed hydrophosphonation, or platinum-catalyzed hydrosilylation as a key step. Surfactants were tested in pentacene or $\alpha$-sexithiophene-based organic field-effect transistors (OFETs) for the modification of the dielectric surface. The studied surfactants increased the effective mobility of the $\alpha$-sexithiophene-based device by up to one order of magnitude. The length of alkyl chain showed to be significant for the pentacene-based device, as the effective mobility only increased in the case of dielectric modification with bithienylundecylphosphonic acid. AFM allowed a better understanding of the morphology of semiconductors on bare $\mathrm{SiO}_{2}$ and surfaces treated with bithienylundecylphosphonic acid.
\end{abstract}

Keywords: bithienyl; chlorodimethylsilane; OFET; pentacene; phosphonic acid; self-assembled monolayer; sexithiophene; surface modification

\section{Introduction}

In the field of organic electronics, increased attention is paid to organic semiconductor interfaces. Organic semiconducting materials (OS) are used as the active layer in many electronic applications, such as organic-field effect transistors (OFET), organic photovoltaic cells, organic light-emitting diodes or memory devices [1].

An organic field-effect transistor (OFET) efficiency is given mainly by the first two layers of the organic semiconductor at the dielectric surface where the charge transfer takes place [2]. Therefore, the quality of the interface between OS and insulator has a crucial role [3-6]. It should be mentioned here that this complex topic includes the impact of various effects. Charge carriers trapping at the organic semiconductor/gate dielectric interface due to the polaron nature of the dielectric surface, the presence of defects and chemical groups of the dielectric surface, and structural defects in the organic semiconductor, or the presence of adsorbed water molecules. In detail, the random orientation of the dipole moments of the gate dielectric surface leads to a significant broadening of the density of states in an organic semiconductor (dipolar electrostatic disorder). Gate dielectric surface with electroactive sites (e.g., hydroxy groups) acts as traps and suppress electron transport. Water molecules adsorbed on the gate dielectric surface also induce charge trapping in p-type organic semiconductors and cause voltage bias-stress instability.

Improvement in the electrical response can be achieved [1,7-9] (increasing mobility or reducing the threshold voltage) by modification of electronic and morphological 
properties of the interface, such as surface functionalization using specially designed organic molecules-surfactants forming a self-assembled monolayer (SAM, Figure 1a) [10]. The surfactant can also improve the wettability of the surface, providing new functionality to the substrate and can affect the structural order of organic semiconductor by directing the growth of semiconductor to obtain the suitable orientation for high FET performance [11-16].

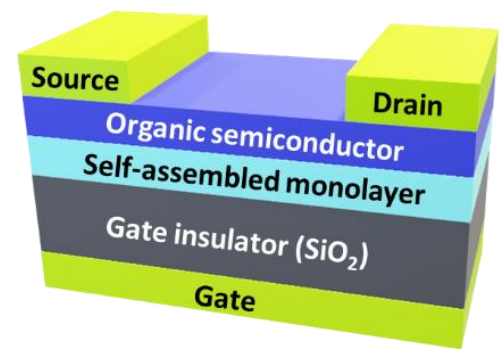

(a)

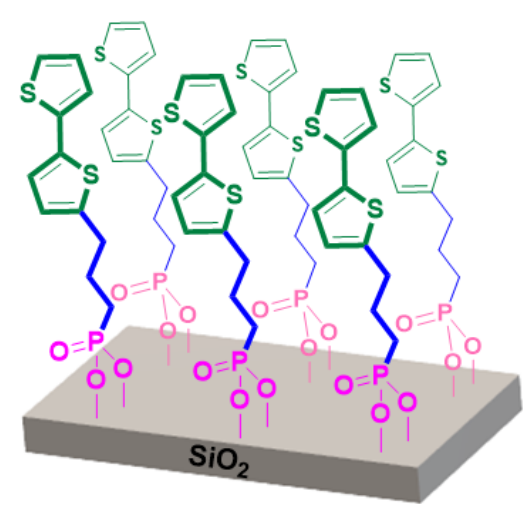

(b)

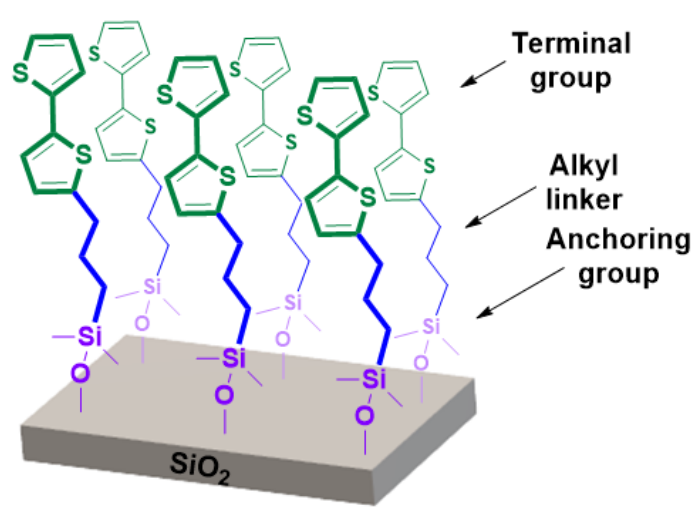

Figure 1. (a) Schematic view of the organic field-effect transistors (OFET) using the active layer of OS deposited on a SAM-modified gate insulator layer; (b) proposed modification of $\mathrm{SiO}_{2}$ surface by $\mathrm{SAM}$ formation with phosphonic acid and silane anchoring group.

The typical structure of such surfactants consists of $\alpha, \omega$-functionalized alkanes with an anchoring group at one end and terminal group at the other end (Figure $1 \mathrm{~b}$ ). The anchoring group is responsible for binding to the dielectric surface. The aliphatic chain contributes to the self-assembling process through interchain van der Waals interactions. The role of the terminal group is either to provide stronger interaction to the OS [9] or to act as an organic semiconductor in monolayer OFET devices [17].

While developing organic semiconductors with bithienyl substituted naphthalenes in our research group [18-20] we found problems with their deposition on the substrate during application in OFET due to low surface wettability, even in the case of the surface processed with commercially available octadecylsilyl trichloride (OTCS). Therefore, we designed surfactants containing bithienyl terminal groups to provide $\pi-\pi$ interaction with our semiconducting materials. For interface modification on $\mathrm{SiO}_{2}, \mathrm{SAMs}$ with silane and phosphonic acid anchoring groups have been widely studied [9,17,21,22]. Since several types of silane anchoring groups, such as tri-, di-, and monochlorosilanes, or trimetoxysilanes, are used in SAM materials and are differing in reactivity, we have chosen the medium moisture-sensitive and medium reactive monochlorosilane group. Phosphono anchoring group was chosen as moisture insensitive, which significantly simplifies their storage and working conditions and does not undergo self-condensation. The designed surfactants were aimed to be tested with two typical p-type organic semiconductorspentacene or sexithiophene in OFET.

The chemical structure of the designed derivatives for the SAM formation is displayed in Figure 2. Each derivative consists of bithienyl terminal group, C8 to C13 alkyl linker and phosphono or chlorodimethylsilyl anchoring group. The bithienyl group should provide $\pi-\pi$ interaction between neighboring molecules in both steps for possible guidance in controlled surface modification and later on for controlled self-assembling of selected semiconducting material on the modified surface. Due to the observed significant oddeven effect of aliphatic linker lengths on molecular packing of SAM [23,24], we selected structures with both even and odd numbers of carbon atoms in the alkyl chain. 

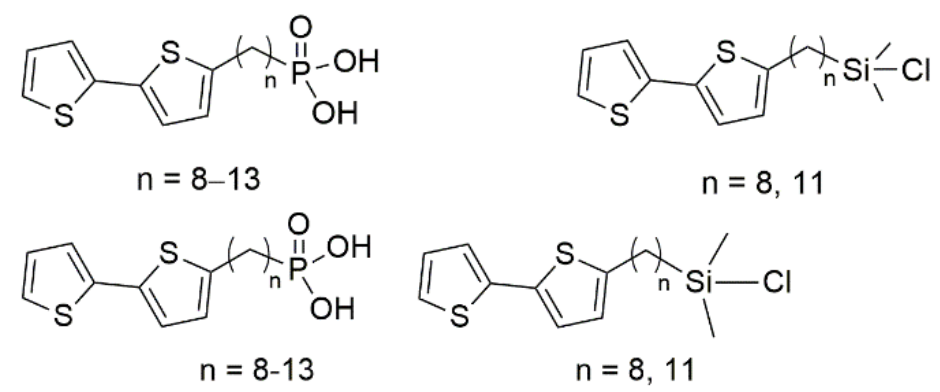

Figure 2. Chemical structures of designed derivatives with phosphono and chlorodimethylsilyl anchoring groups.

\section{Materials and Methods}

\subsection{Materials}

Solvents were purified by standard methods before use [25]. The 4,4,5,5-tetramethyl1,3,2-dioxaphospholane 2-oxide was purchased from TCI Chemicals (TCI Europe N. V.Tokyo Chemical Industry, Brussels, Belgium). All bromoalkenes, 1,8-dibromooctane, bithiophene, and tetrakis(triphenylphosphine)palladium $(0)\left(\mathrm{Pd}\left(\mathrm{PPh}_{3}\right)_{4}\right)$ were purchased from Fluorochem. n-Butyllithium (1.6 M solution in hexane), Karstedt's catalyst and chlorodimethylsilane were purchased from Sigma Aldrich (Merck, KGaA, Darmstadt, Germany), and bromotrimethylsilane was purchased from Acros Organics (Thermo Fisher Scientific, Geel, Belgium). All chemicals were used as purchased without further purification. Thin-layer chromatography was performed on Merck TLC plates of silica gel 60, F-254, visualization under UV $254 \mathrm{~nm}$ and $365 \mathrm{~nm}$, for column chromatography was used silica gel 60 (Merck).

\subsection{Experiment}

\subsubsection{Synthesis of $\omega$-Bromoalk-1-enes $(\mathbf{1 e}-\mathbf{f})$}

To a combined solution of $\mathrm{LiCl}\left(254 \mathrm{mg}, 6 \mathrm{mmol}, 12 \mathrm{~mL}\right.$ THF) and $\mathrm{CuCl}_{2}(403 \mathrm{mg}$, $3 \mathrm{mmol}, 12 \mathrm{~mL}$ THF), which was stirred overnight, 1,8-dibromooctane ( $4.08 \mathrm{~g}, 15 \mathrm{mmol})$ was added in one portion. The reaction mixture was cooled to $0{ }^{\circ} \mathrm{C}$, and but-3-en-1ylmagnesium bromide $\left(2.43 \mathrm{~g}, 18 \mathrm{mmol}, 10 \mathrm{~mL}\right.$ of $2 \mathrm{M}$ solution in $\mathrm{Et}_{2} \mathrm{O}$ ) was added through a cannula. After addition, the mixture was stirred overnight at room temperature. Then, $1 \mathrm{M} \mathrm{HCl}$ was added, and the mixture was stirred for another $30 \mathrm{~min}$. The aqueous layer was extracted with diethyl ether. Combined organic layers were washed with brine, dried over $\mathrm{Na}_{2} \mathrm{SO}_{4}$, and the solvent was evaporated. The crude mixture was separated by flash chromatography $\left(\mathrm{SiO}_{2}\right.$, hexanes). Further characterizations are reported in Supplementary Materials.

\subsubsection{General Procedure for Preparation of 5-(Alk- $\omega$-en-1-yl)-2,2'-bithiophenes (2a-f)}

To a solution of bithiophene $(39.00 \mathrm{~g}, 234 \mathrm{mmol})$ in dry THF $(20 \mathrm{~mL}), n-\operatorname{BuLi}(27 \mathrm{~mL}$, $43 \mathrm{mmol}$ ) was added dropwise at $0{ }^{\circ} \mathrm{C}$. The reaction mixture was allowed to warm to room temperature and stirred for an additional $20 \mathrm{~min}$. Then, corresponding $\omega$-bromoalkene $(4.9 \mathrm{~mL}, 29 \mathrm{mmol})$ was added, and the mixture was refluxed overnight. After cooling to room temperature, water $(40 \mathrm{~mL})$ was added, and the organic phase was separated. The aqueous phase was extracted with dichloromethane $(3 \times 40 \mathrm{~mL})$. The combined organic phases were dried over $\mathrm{Na}_{2} \mathrm{SO}_{4}$, filtered through $\mathrm{SiO}_{2}$ pad and after the evaporation of the solvent, the product was purified by vacuum distillation. Further characterizations are reported in Supplementary Materials.

2.2.3. General Procedure for 2-[ $\omega-\left(2,2^{\prime}\right.$-Bithiophen-5-yl)alkyl]dioxaphospholane 2-oxides (3a-f)

Corresponding 5-(alk- $\omega$-enyl)-2,2'-bithiophene (500 mg, $1.8 \mathrm{mmol}), 4,4,5,5$-tetramethyl1,3,2-dioxaphospholane 2-oxide (300 mg, $1.8 \mathrm{mmol}$.) and $\mathrm{Pd}\left(\mathrm{PPh}_{3}\right)_{4}(106 \mathrm{mg}, 0.9 \mathrm{mmol}$, 
0.05 equiv.) were dissolved in dry toluene $(6 \mathrm{~mL})$ in Schlenk flask. The mixture was heated at $110^{\circ} \mathrm{C}$ for $12 \mathrm{~h}$. The solvent was removed under vacuum, and the crude product was purified by chromatography on silica gel with hexanes and ethyl acetate $(0 \rightarrow 100 \%$ EtOAc) as eluents. Further characterizations are reported in Supplementary Materials.

\subsubsection{General Synthesis of $\omega-\left(2,2^{\prime}\right.$-Bithiophen-5-yl)alkylphosphonic Acids TTCnP}

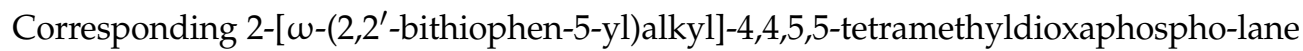
2-oxide $(500 \mathrm{mg}, 1.1 \mathrm{mmol})$ was dissolved in dry dichloromethane $(5 \mathrm{~mL})$ and $\mathrm{BrSiMe}_{3}$ (450 mg, $2.9 \mathrm{mmol}, 2.5$ equiv.) was added dropwise at $0{ }^{\circ} \mathrm{C}$. The reaction mixture was stirred at $40{ }^{\circ} \mathrm{C}$ for $3 \mathrm{~h}$, then allowed to stir at room temperature overnight. The solvent was removed, and the remaining solid was dissolved in methanol, and the product was precipitated with pentane. The solid was filtered and washed with pentane. Further characterizations are reported in Supplementary Materials.

\subsubsection{General Synthesis of $\omega$-(2,2'-Bithiophen-5-yl)alkylchlorodimethylsilanes TTCnSi}

To corresponding 5-(alk- $\omega$-enyl)-2,2' -bithiophene $(5.43 \mathrm{mmol})$ in dry toluene $(100 \mathrm{~mL})$, chlorodimethylsilane (13.7 mL, $11.80 \mathrm{~g}, 108 \mathrm{mmol}, 20$ equiv.) and Karstedt's catalyst $\left(108 \mu \mathrm{L}, 2 \% \mathrm{Pt}\right.$ in xylene, $0.16 \mathrm{mmol}, 0.03$ equiv.) were added at $32{ }^{\circ} \mathrm{C}$. The reaction mixture was stirred at $35{ }^{\circ} \mathrm{C}$ overnight. The unreacted chlorodimethylsilane and solvent were removed by distillation, and the greenish residue was purified by bulb-to-bulb distillation under reduced pressure $\left(203{ }^{\circ} \mathrm{C} / 0.4\right.$ Torr $)$. Further characterizations are reported in Supplementary Materials.

\subsection{Device Fabrication}

The organic field-effect (OFET) devices have been fabricated in top-contact geometry. Heavily doped silicon wafers (boron-doped, 1-10 $\Omega \cdot \mathrm{cm}$ ) were used as the substrates, where the thermally grown oxide $\left(\mathrm{SiO}_{2}\right)$ of $110 \mathrm{~nm}$ has been used as a gate insulator layer with a capacitance per unit of area of $33 \mathrm{nF} / \mathrm{cm}^{2}$. Prior to the organic film deposition, the substrates were sonicated in isopropyl alcohol and pure water, consecutively, and then cleaned up by UV/ozone treatment. SAM materials were dissolved in methanol with a concentration of $0.5 \mathrm{wt}$.\%. Silicon substrates were immersed in SAM solution for $48 \mathrm{~h}$ in an inert atmosphere (nitrogen). Organic semiconductors pentacene or $\alpha$-sexithiophene (both from Merck) were deposited onto bare and SAM-modified substrates using SPECTROS 100 deposition system (Kurt J. Lesker, East Sussex, UK) by thermal evaporation from a Knudsen cell $\left(\mathrm{Al}_{2} \mathrm{O}_{3}\right.$ crucible) in a vacuum better than $10^{-4} \mathrm{~Pa}$. The deposition rate was fixed at $3 \mathrm{~nm} / \mathrm{min}$ and monitored by a quartz crystal microbalance (Kurt J. Lesker, East Sussex, UK). Copper electrodes were subsequently deposited by thermal evaporation in a vacuum through the shadow mask. The channel length varied from 50 to $200 \mu \mathrm{m}$, whereas the channel width was $2 \mathrm{~mm}$ for all the fabricated devices. All output and transfer characteristics of fabricated OFET devices of the structure shown in Figure 1 were measured in an ambient atmosphere.

\subsection{Characterization}

Melting points were determined with a Melting Point M-656 Büchi (BÜCHI Labortechnik AG, Flawil, Switzerland) apparatus and were uncorrected. IR spectra were determined with a Agilent Cary 630 FTIR Spectrometer (Agilent Technologies, Santa Clara, CA, USA). NMR spectra were recorded on the Varian VNMRS (Agilent Technologies Inc., Palo Alto, CA, USA) (600 MHz for ${ }^{1} \mathrm{H}, 151 \mathrm{MHz}$ for ${ }^{13} \mathrm{C}$, and $243 \mathrm{MHz}$ for $\left.{ }^{31} \mathrm{P}\right)$. Chemical shifts are reported in $\delta \mathrm{ppm}$ referenced to an internal $\mathrm{SiMe}_{4}$ standard for ${ }^{1} \mathrm{H} \mathrm{NMR}$, and all measurements were performed at $20^{\circ} \mathrm{C}$ if not stated differently. Compounds were measured in chloroform- $d 1\left(\mathrm{CDCl}_{3}\right)$ or dimethyl sulfoxide- $d 6$ (DMSO) The following abbreviations are used: $\mathrm{s}=$ singlet, $\mathrm{d}=$ doublet, $\mathrm{dd}=$ doublet of doublets, $\mathrm{t}=$ triplet, $\mathrm{q}=$ quartet, $\mathrm{m}=$ multiplet. HRMS was determined with an Orbitrap Velos Pro (Thermo Fisher Scientific Inc., 
Waltham, MS, USA). The spectral characteristics of synthesized compounds are reported in Supplementary Materials.

The fabricated devices were characterized by standard steady-state current-voltage measurement using the $4155 \mathrm{C}$ Semiconductor Parameter Analyzer (Agilent Technologies, CA, USA) to determine threshold voltages and effective mobilities.

Surface morphology study of organic films was performed with the Dimension Edge Atomic Force Microscope (AFM) system (Veeco Instruments, CA, USA) operating in the tapping mode. The AFM probe (model FESPA-V2 from Bruker, MA, USA) with a soft cantilever (nominal spring constant, $k=2.8 \mathrm{~N} / \mathrm{m}$ ) was used to measure the film surface. The nominal tip radius was $8 \mathrm{~nm}$. The AFM images have been captured over the area of $1.2 \times 1.2 \mu \mathrm{m}^{2}$ and $2.4 \times 2.4 \mu \mathrm{m}^{2}$ for $\alpha$-sexithiophene or pentacene films, respectively. The surface morphology images were taken from the middle of the OFET channels.

\section{Results and Discussion}

\subsection{Synthesis of Surfactants}

The synthetic strategy towards derivatives with phosphono anchoring group is outlined in Scheme 1. While shorter $\omega$-bromoalkenes were commercially available, longer bromoalkenes $\mathbf{1 e}$ and $\mathbf{1} \mathbf{f}$ were synthesized by previously described copper-catalyzed crosscoupling from 1,8-dibromooctane and corresponding Grignard reagent [26,27]. The formation of disubstituted products causes a lower yield of these derivatives. However, these by-products can be easily separated by column chromatography. The bithienyl alkenes $\mathbf{2 a}-\mathbf{f}$ were obtained by the reaction of in-situ prepared 2-bithienyllithium with $\omega$-bromoalkenes in good yields from $70 \%$ to $86 \%$. Excess bithiophene in the reaction mixture was distilled off, and the residue was further purified by column chromatography. The synthesis of undecenylbithiophene $\mathbf{2} \mathbf{f}$ has been previously described by Muzafarov et al. [28]. The monoalkylated bithiophenes $\mathbf{2} \mathbf{a}-\mathbf{f}$ were converted to dioxaphospholane oxides $\mathbf{3 a}-\mathbf{f}$ by Tanaka-Pd catalyzed hydrophosphorylation [29] using pinacol phosphonate (4). Alkylphosphonic acids TTCnP $(n=8-13)$ were obtained by treating corresponding dioxaphospholane oxides 3a-f with $\mathrm{BrSiMe}_{3}[30,31]$ followed by anhydrous methanol [32] in good yields. All derivatives were characterized by ${ }^{1} \mathrm{H},{ }^{13} \mathrm{C},{ }^{31} \mathrm{P}$ NMR, HRMS and FTIR. In some cases, 2D NMR was recorded to assign split carbon signals due to ${ }^{13} \mathrm{C}-{ }^{31} \mathrm{P}$ coupling.

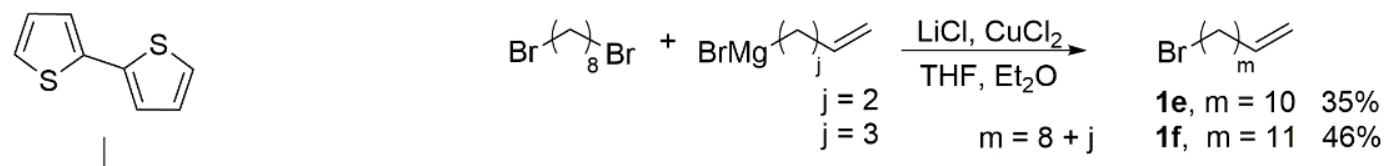

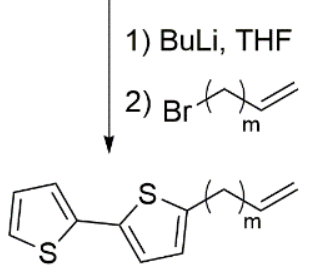

2a, $m=6 \quad 73 \%$

2b, $m=7 \quad 80 \%$

2c, $m=8 \quad 82 \%$

2d, $m=9 \quad 81 \%$

$2 e, m=10 \quad 86 \%$

2f, $m=11 \quad 70 \%$
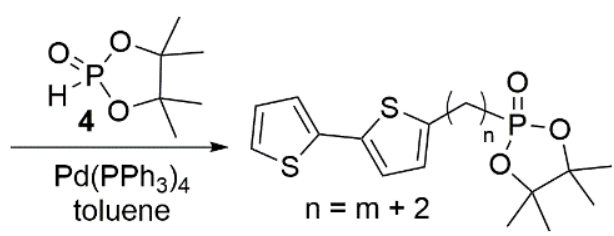

3a, $n=8 \quad 50 \%$

$3 b, n=9 \quad 45 \%$

$3 c, n=10 \quad 43 \%$

$3 d, n=1140 \%$

$3 e, n=12 \quad 42 \%$

3f, $n=13 \quad 45 \%$

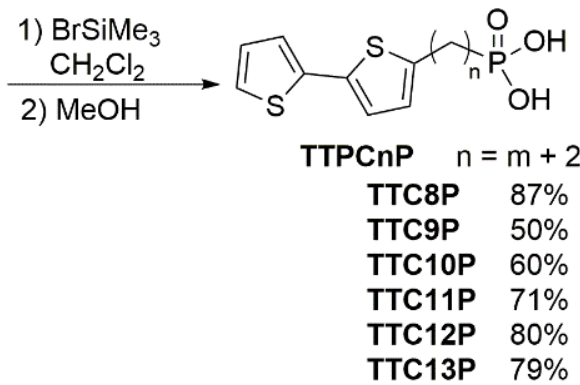

Scheme 1. Synthesis of derivatives for surface modification TTCnP with phosphono anchoring group and various lengths of alkyl linker.

The chlorosilane derivatives TTCnSi $(n=8,11)$ were obtained by a hydrosilylation reaction of bithienyl alkenes with chlorodimethylsilane in the presence of Karstedt's catalyst (Scheme 2). Despite high conversion in these reactions, yields of the corresponding products TTCnSi were relatively low due to partial decomposition in vacuum distillation. 
We verified the presence of chlorine atom in the silane group by controlled hydrolysis confirmed by ${ }^{1} \mathrm{H}$ NMR. After measurement of ${ }^{1} \mathrm{H}$ NMR spectrum of the products TTCnSi, water was added to the NMR tube, and the ${ }^{1} \mathrm{H}$ NMR spectrum was remeasured. Hydrolysis caused the change in shifts of silane methyl groups from 0.47 for $\mathbf{R S i M e}_{2} \mathrm{Cl}$ to $0.14 \mathrm{ppm}$ for $\mathrm{RSiMe}_{2} \mathrm{OH}$ (Figure 3).

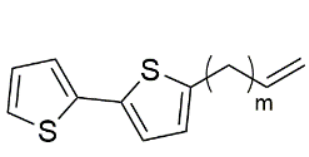

2a, $m=6$

2d, $m=9$

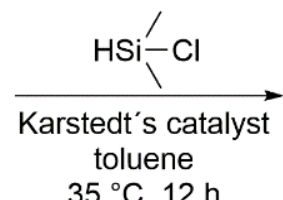

$35^{\circ} \mathrm{C}, 12 \mathrm{~h}$

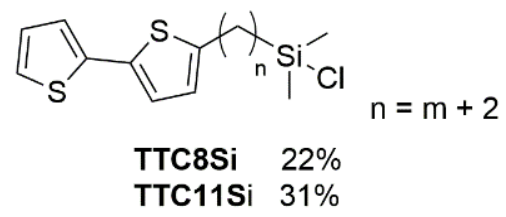

Scheme 2. Synthesis of derivatives for surface modification TTCnSi with chlorodimethylsilyl anchoring group.
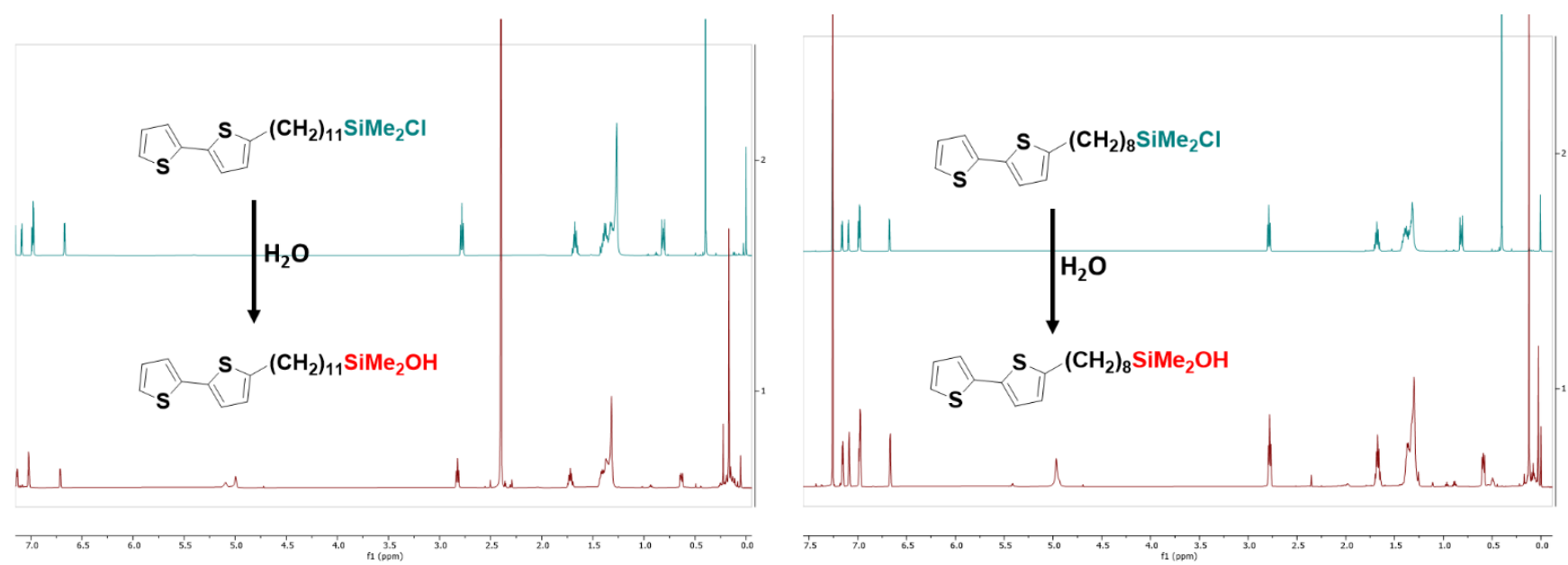

Figure 3. Changes observed in ${ }^{1} \mathrm{H}$ NMR spectrum of chlorodimethylsilane derivatives TTCnSi by hydrolysis.

\subsection{OFET Performance}

Pentacene and $\alpha$-sexithiophene have been chosen as representative of typical and widely used organic semiconductors. Typical output characteristics of pentacene OFET devices with organic semiconductor layer deposited on bare $\mathrm{SiO}_{2}$ surface or SAM-modified surface are depicted in Figure 4. All fabricated devices exhibited standard transistor behavior. The surface modification does not influence the device performance significantly for the SAM with TTC11Si (chlorodimethylsilyl anchoring group), whereas the SAM with TTC11P (phosphono anchoring group) increases the output currents.

The transfer characteristics have been used to evaluate the threshold voltage and the saturated effective mobility for all devices, as depicted in Figure 5. Interestingly, for pentacene-based devices, the effective mobility is slightly reduced with increasing alkyl chain length of phosphono-based surfactants TTCnP and significantly rises for an alkyl chain length of $n=11$. Surprisingly, the SAM with TTCnSi ( $\mathrm{SiMe}_{2} \mathrm{Cl}$ anchoring group) does not follow this tendency, and the effective mobility is suppressed. The anchoring groups are greatly affecting the packing density and molecular orientation. As a result, the bithienyl terminal group and pentacene have different interactions due to change mutual order. It should be noted here that since the organic semiconductors exhibit a certain distribution of material parameters, the effective mobility has been evaluated from a group of devices and the standard deviation was estimated (plotted as an error bar in Figure 5). The other way to verify the credibility of claimed effective mobilities is the evaluation of the reliability factor $r$ [4]. The pentacene-based devices exhibit the reliability factor $r$ of $92 \% \pm 12 \%$, whereas the $\alpha$-sexithiophene-based devices had reliability factor on the level of $86 \% \pm 12 \%$. The trend 
of effective mobility is not accompanied by the threshold voltage that is almost conserved. The conservation of the threshold voltage indicates that the SAM modification does not cause additional trapping states on the organic semiconductor/gate insulator interface. On the other hand, the $\alpha$-sexithiophene OFET devices exhibit a significant increase in effective mobility for all investigated SAM modifications of gate insulator surface. The threshold voltage is greatly shifted from a positive voltage to a zero value or a negative one. Observed shift points out the modification of the internal electric field due to charge trapping and/or interfacial dipole. Here, the SAM with silyl surfactants TTCnSi reaches almost identical results as the SAM with phosphono-based TTCnP.
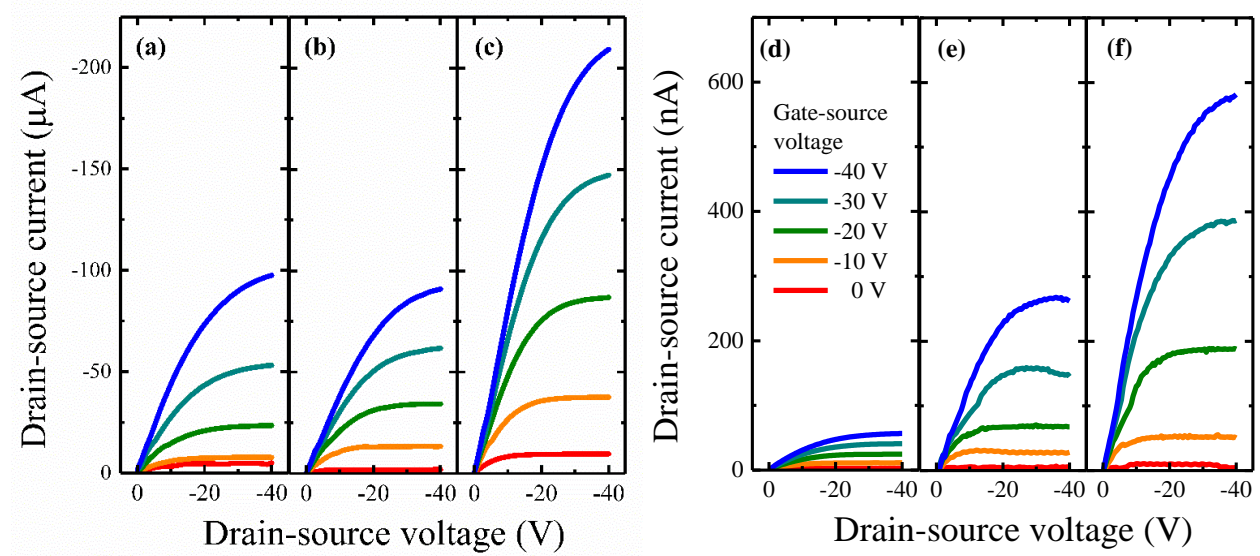

Figure 4. Output characteristics of pentacene OFET devices (channel length $L$ of $50 \mu \mathrm{m}$ ) with $(\mathbf{a}-\mathbf{c})$ pentacene or $(\mathbf{d}-\mathbf{f}) \alpha$-sexithiophene layer deposited on $(\mathbf{a}, \mathbf{d})$ bare $\mathrm{SiO}_{2}$ surface or SAM-modified surface with (b,e) TTC11Si and (c,f) TTC11P.
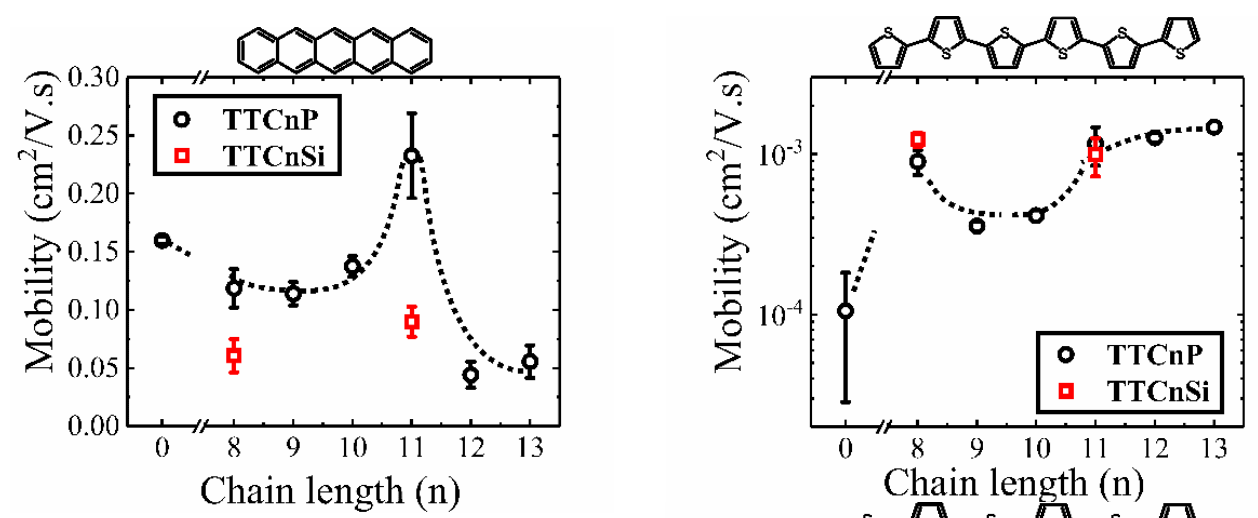

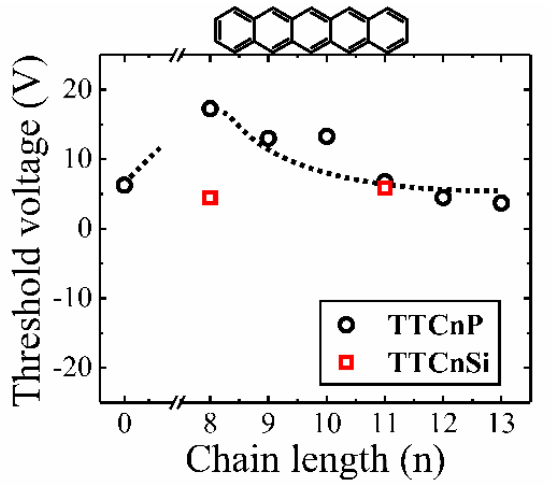

(a)

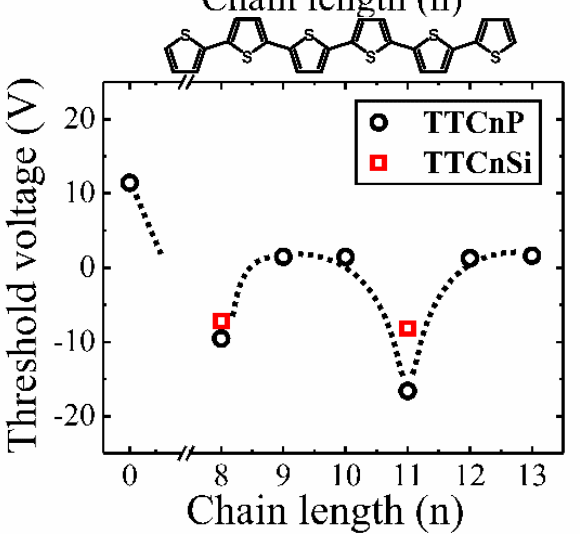

(b)

Figure 5. Effective mobilities and threshold voltages for (a) pentacene or (b) $\alpha$-sexithiophene OFETs using bare and SAM-modified substrates. 


\subsection{Surface Morphology}

The thin-film morphology of the $\alpha$-sexithiophene or pentacene film deposited on bare $\mathrm{SiO}_{2}$ and modified by TTC11P were analyzed by the Atomic Force Microscopy (AFM). The AFM images were taken from the middle of the transistor channel for both vacuum-deposited thin films onto bare and SAM treated surfaces. Figure 6 illustrates the $\alpha$ sexithiophene films. The organic semiconductor forms elongated crystals with an average crystal length of $125 \pm 29 \mathrm{~nm}$ on bare $\mathrm{SiO}_{2}$, whereas the length reaches $92 \pm 26 \mathrm{~nm}$ on SAM treated surface. It should be noted here that according to the quartz crystal microbalance (QCM) measurement, the average film thickness of the deposited film was $100 \mathrm{~nm}$ and the AFM morphology revealed a similar height distribution range. In other words, the $\alpha$-sexithiophene film is most probably not fully covering the substrate surface, and the charge transfer is due to the percolation mechanism.
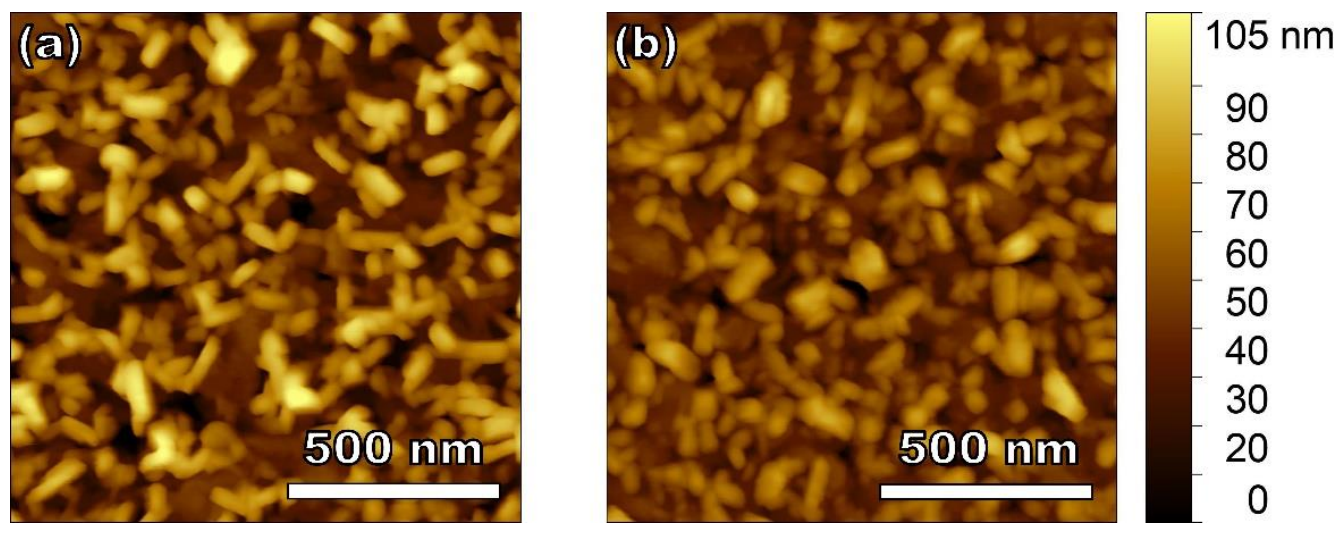

Figure 6. Surface morphology of $\alpha$-sexithiophene layer deposited on (a) bare $\mathrm{SiO}_{2}$ or (b) TTC11P modified surface.

Figure 7 depicts the surface morphology of pentacene films. Pentacene displays polymorphism in its crystalline structure with two different phases [33-35]. Pentacene molecules onto the $\mathrm{SiO}_{2}$ surface form the "thin-film phase", where the orthorhombic structure occurs. On the other hand, the "bulk phase" observed for thick film refers to the triclinic structure. The thin-film phase represents the layer-by-layer growth of pentacene films on a substrate surface. Hence, the incomplete layers, the terraces, have singlemolecule thickness and are characterized by the inter-planar spacing $d_{001}=1.54 \mathrm{~nm}$ [33]. The pentacene films deposited on bare $\mathrm{SiO}_{2}$, shown in Figure 7a, exhibit terraces separated by steps of $1.5 \pm 0.5 \mathrm{~nm}$, and the presence of double layers is almost negligible, as shown in Figure 8a. Interestingly, the pentacene films deposited on TTC11P treated surface have obviously smaller grains with not well-defined terraces. Note that even though pentacene grains on SAM treated surfaces are usually smaller than those on $\mathrm{SiO}_{2}$, pentacene deposited on SAM has a lower defect density than pentacene on bare $\mathrm{SiO}_{2}[36,37]$. The absence of observable flat terraces points out the presence of other molecular orientations. Once the bulk phase nucleates onto the thin-film phase, the coexistence of different structural phases causes smoothing of incrementation steps $[35,38]$. As a result, the SAM treatment causes an earlier transition from the thin-film phase to the bulk phase of pentacene films. It improves the effective mobility by a greatly larger contribution than it is mobility suppression due to the higher density of grain boundaries 

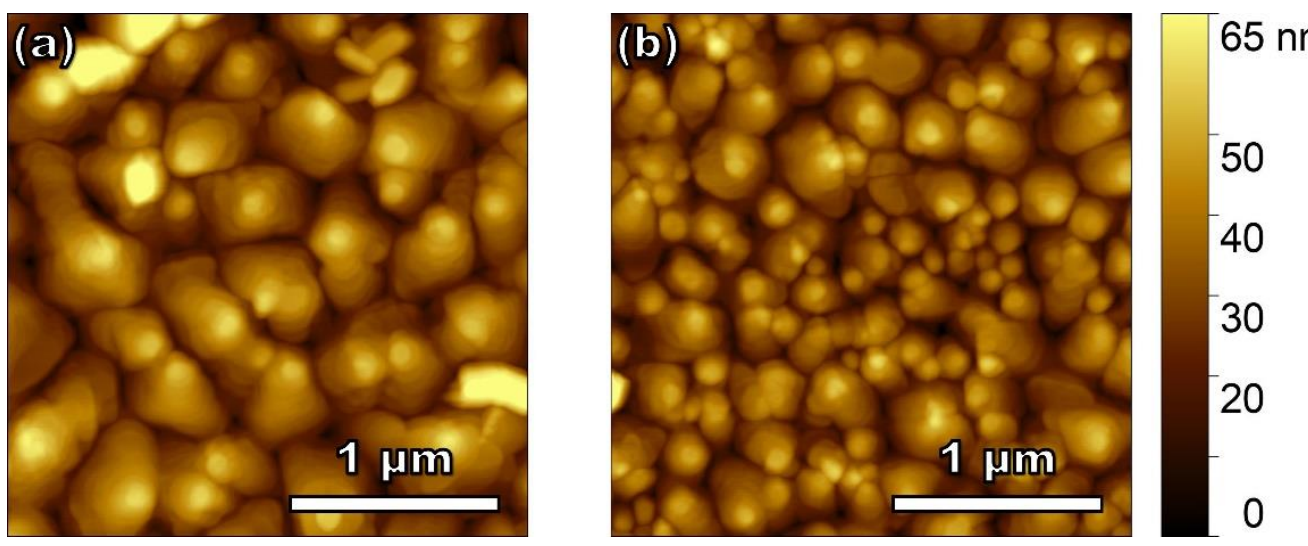

Figure 7. Surface morphology of pentacene layer deposited on (a) bare $\mathrm{SiO}_{2}$ or (b) TTC11P modified surface.

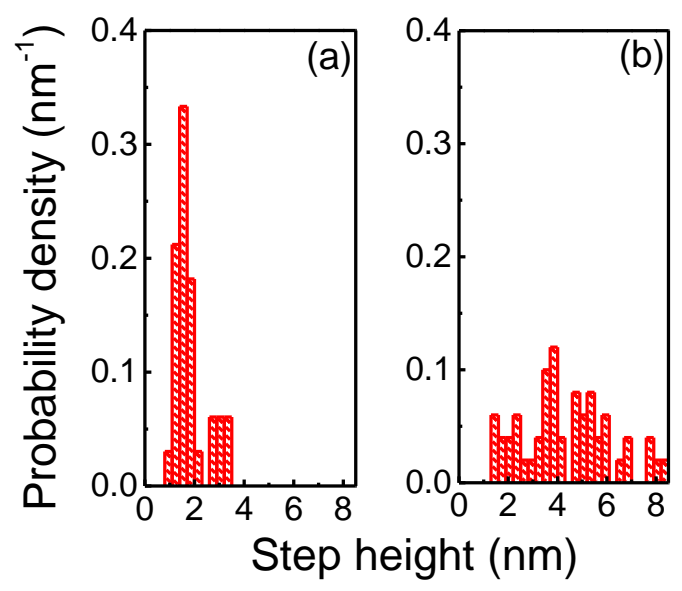

Figure 8. Probability density distribution of pentacene layer step heights for films deposited on (a) bare $\mathrm{SiO}_{2}$ or (b) TTC11P modified surface.

\section{Conclusions}

In summary, we synthesized new surfactants with phosphono or chlorodimethylsilyl anchoring groups and various alkyl chain lengths by up to three-step synthesis. In the case of pentacene-based OFET, TTC11P surfactant showed a significant increase in effective mobility. The effective mobility of $\alpha$-sexithiophene-based transistor increased in all cases of surface treatment with our surfactants. Investigation of the surface morphology showed that surface treatment with TTC11P causes the formation of smaller grains of pentacene with lower defect density and therefore results in higher mobility compared to OFET device with bare $\mathrm{SiO}_{2}$. Application of our organic semiconductors with bithienyl surfactants in OFET is under research.

Supplementary Materials: The following are available online at https:/ / www.mdpi.com/article/10

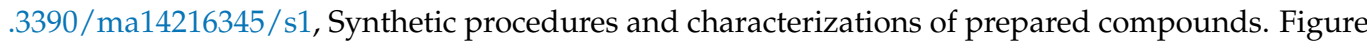
S1-S59: ${ }^{1} \mathrm{H},{ }^{13} \mathrm{C}$ and ${ }^{31} \mathrm{P}$ NMR spectra.

Author Contributions: Conceptualization and supervision, M.W. and M.P. (Martin Putala); investigationsynthesis and characterization, L.F. and I.K.; investigation-OFET, M.M.; investigation-AFM, M.P. (Milan Pavúk); writing—original draft preparation, L.F.; writing—review and editing, M.W. and M.P. (Martin Putala). All authors have read and agreed to the published version of the manuscript.

Funding: This research was financially supported by the Research and Development Agency of the Slovak Republic, grant No. APVV-17-0501, the Scientific Grant Agency of the Slovak Republic, Grant No. 1/0452/19 and by the European Union's Horizon 2020 research and innovation programme under grant agreement No. 810701 . 
Institutional Review Board Statement: Not applicable.

Informed Consent Statement: Not applicable.

Data Availability Statement: Data is contained within this article or its Supplementary Materials.

Conflicts of Interest: The authors declare no conflict of interest.

\section{References}

1. Fahlman, M.; Fabiano, S.; Gueskine, V.; Simon, D.; Berggren, M.; Crispin, X. Interfaces in organic electronics. Nat. Rev. Mater. 2019, 4, 627-650. [CrossRef]

2. Haneef, H.F.; Zeidell, A.M.; Jurchescu, O.D. Charge carrier traps in organic semiconductors: A review on the underlying physics and impact on electronic devices. J. Mater. Chem. C 2020, 8, 759-787. [CrossRef]

3. Guo, X.; Xu, Y.; Ogier, S.; Ng, T.N.; Caironi, M.; Perinot, A.; Li, L.; Zhao, J.; Tang, W.; Sporea, R.A.; et al. Current Status and Opportunities of Organic Thin-Film Transistor Technologies. IEEE Trans. Electron Devices 2017, 64, 1906-1921. [CrossRef]

4. Choi, H.H.; Cho, K.; Frisbie, C.D.; Sirringhaus, H.; Podzorov, V. Critical assessment of charge mobility extraction in FETs. Nat. Mater. 2017, 17, 2-7. [CrossRef]

5. $\quad$ Flesch, H.G.; Mathijssen, S.G.J.; Gholamrezaie, F.; Moser, A.; Neuhold, A.; Novák, J.; Ponomarenko, S.A.; Shen, Q.; Teichert, C.; Hlawacek, G.; et al. Microstructure and phase behavior of a quinquethiophene-based self-assembled monolayer as a function of temperature. J. Phys. Chem. C 2011, 115, 22925-22930. [CrossRef]

6. Yan, Y.; Zhao, Y.; Liu, Y. Recent progress in organic field-effect transistor-based integrated circuits. J. Polym. Sci. 2021. [CrossRef]

7. Casalini, S.; Bortolotti, C.A.; Leonardi, F.; Biscarini, F. Self-assembled monolayers in organic electronics. Chem. Soc. Rev. 2017, 46, 40-71. [CrossRef]

8. Mottaghi, M.; Horowitz, G. Field-induced mobility degradation in pentacene thin-film transistors. Org. Electron. 2006, 7, 528-536. [CrossRef]

9. Liu, D.; Miao, Q. Recent progress in interface engineering of organic thin film transistors with self-assembled monolayers. Mater. Chem. Front. 2018, 2, 11-21. [CrossRef]

10. Singh, M.; Kaur, N.; Comini, E. The role of self-assembled monolayers in electronic devices. J. Mater. Chem. C 2020, 8, 3938-3955. [CrossRef]

11. Lee, H.S.; Kim, D.H.; Cho, J.H.; Hwang, M.; Jang, Y.; Cho, K. Effect of the phase states of self-assembled monolayers on pentacene growth and thin-film transistor characteristics. J. Am. Chem. Soc. 2008, 130, 10556-10564. [CrossRef]

12. Lee, H.S.; Kim, D.H.; Cho, J.H.; Park, Y.D.; Kim, J.S.; Cho, K. Enhancement of interconnectivity in the channels of pentacene thin-film transistors and its effect on field-effect mobility. Adv. Funct. Mater. 2006, 16, 1859-1864. [CrossRef]

13. Bent, S.F. Heads or tails: Which is more important in molecular self-assembly? ACS Nano 2007, 1, 10-12. [CrossRef] [PubMed]

14. Chiodi, M.; Gavioli, L.; Beccari, M.; Di Castro, V.; Cossaro, A.; Floreano, L.; Morgante, A.; Kanjilal, A.; Mariani, C.; Betti, M.G. Interaction strength and molecular orientation of a single layer of pentacene in organic-metal interface and organic-organic heterostructure. Phys. Rev. B-Condens. Matter Mater. Phys. 2008, 77. [CrossRef]

15. Reig, M.; Bagdziunas, G.; Ramanavicius, A.; Puigdollers, J.; Velasco, D. Interface engineering and solid-state organization for triindole-based p-type organic thin-film transistors. Phys. Chem. Chem. Phys. 2018, 20, 17889-17898. [CrossRef]

16. Bujaldón, R.; Puigdollers, J.; Velasco, D. Towards the bisbenzothienocarbazole core: A route of sulfurated carbazole derivatives with assorted optoelectronic properties and applications. Materials 2021, 14, 3487. [CrossRef]

17. Borshchev, O.V.; Ponomarenko, S.A. Self-assembled organic semiconductors for monolayer field-effect transistors. Polym. Sci.-Ser. C 2014, 56, 32-46. [CrossRef]

18. Filo, J.; Mišicák, R.; Cigáň, M.; Weis, M.; Jakabovič, J.; Gmucová, K.; Pavúk, M.; Dobročka, E.; Putala, M. Oligothiophenes with the naphthalene core for organic thin-film transistors: Variation in positions of bithiophenyl attachment to the naphthalene. Synth. Met. 2015, 202, 73-81. [CrossRef]

19. Mišicák, R.; Novota, M.; Weis, M.; Cigáň, M.; Šiffalovič, P.; Nádaždy, P.; Kožíšek, J.; Kožǐ̌́ková, J.; Pavúk, M.; Putala, M. Effect of alkyl side chains on properties and organic transistor performance of 2,6-bis(2,2'-bithiophen-5-yl)naphthalene. Synth. Met. 2017, 233, 1-14. [CrossRef]

20. Feriancová, L.; Cigáň, M.; Gmucová, K.; Kožíšek, J.; Nádaždy, V.; Putala, M. Effect of electron-withdrawing groups on molecular properties of naphthyl and anthryl bithiophenes as potential n-type semiconductors. New J. Chem. 2021, 45, 9794-9804. [CrossRef]

21. Haensch, C.; Schubert, U.S.; Hoeppener, S. Chemical modification of self-assembled silane based monolayers by surface reactions. Chem. Soc. Rev. 2010, 39, 2323-2334. [CrossRef] [PubMed]

22. Queffélec, C.; Petit, M.; Janvier, P.; Knight, D.A.; Bujoli, B. Surface modification using phosphonic acids and esters. Chem. Rev. 2012, 112, 3777-3807. [CrossRef] [PubMed]

23. Krzykawska, A.; Szwed, M.; Ossowski, J.; Cyganik, P. Odd-Even Effect in Molecular Packing of Self-Assembled Monolayers of Biphenyl-Substituted Fatty Acid on Ag(111). J. Phys. Chem. C 2018, 122, 919-928. [CrossRef]

24. Stoliar, P.; Kshirsagar, R.; Massi, M.; Annibale, P.; Albonetti, C.; De Leeuw, D.M.; Biscarini, F. Charge injection across self-assembly monolayers in organic field-effect transistors: Odd-even effects. J. Am. Chem. Soc. 2007, 129, 6477-6484. [CrossRef] [PubMed]

25. Armarego, W.L.F.; Chai, C. Purification of Laboratory Chemicals, 5th ed.; Butterworth-Heinemann: Amsterdam, The Netherlands, 2003; ISBN 9780123821614. 
26. Christoffers, J.; Oertling, H. Intramolecular Michael reactions by iron(III) catalysis. Tetrahedron 2001, 56, 1339-1344. [CrossRef]

27. Johnson, D.K.; Donohoe, J.; Kang, J. Dilithium tetrachlorocuprate catalyzed coupling of allylmagnesium bromide with a,codihaloalkanes. Synth. Commun. 1994, 24, 1557-1564. [CrossRef]

28. Ponomarenko, S.A.; Borshchev, O.V.; Meyer-Friedrichsen, T.; Pleshkova, A.P.; Setayesh, S.; Smits, E.C.P.; Mathijssen, S.G.J.; De Leeuw, D.M.; Kirchmeyer, S.; Muzafarov, A.M. Synthesis of monochlorosilyl derivatives of dialkyloligothiophenes for self-assembling monolayer field-effect transistors. Organometallics 2010, 29, 4213-4226. [CrossRef]

29. Han, L.B.; Mirzaei, F.; Zhao, C.Q.; Tanaka, M. High reactivity of a five-membered cyclic hydrogen phosphonate leading to development of facile palladium-catalyzed hydrophosphorylation of alkenes. J. Am. Chem. Soc. 2000, 122, 5407-5408. [CrossRef]

30. McKenna, C.E.; Higa, M.T.; Cheung, N.H.; McKenna, M.C. The facile dealkylation of phosphonic acid dialkyl esters by bromotrimethylsilane. Tetrahedron Lett. 1977, 18, 155-158. [CrossRef]

31. McKenna, C.E.; Schmidhuser, J. Functional selectivity in phosphonate ester dealkylation with bromotrimethylsilane. J. Chem. Soc. Chem. Commun. 1979, 739. [CrossRef]

32. Reichwein, J.F.; Pagenkopf, B.L. New mixed phosphonate esters by transesterification of pinacol phosphonates and their use in aldehyde and ketone coupling reactions with nonstabilized phosphonates. J. Org. Chem. 2003, 68, 1459-1463. [CrossRef] [PubMed]

33. Ruiz, R.; Mayer, A.C.; Malliaras, G.G.; Nickel, B.; Scoles, G.; Kazimirov, A.; Kim, H.; Headrick, R.L.; Islam, Z. Structure of pentacene thin films. Appl. Phys. Lett. 2004, 85, 4926-4928. [CrossRef]

34. Käfer, D.; Ruppel, L.; Witte, G. Growth of pentacene on clean and modified gold surfaces. Phys. Rev. B-Condens. Matter Mater. Phys. 2007, 75, 085309. [CrossRef]

35. Cheng, H.L.; Mai, Y.S.; Chou, W.Y.; Chang, L.R.; Liang, X.W. Thickness-dependent structural evolutions and growth models in relation to carrier transport properties in polycrystalline pentacene thin films. Adv. Funct. Mater. 2007, 17, 3639-3649. [CrossRef]

36. Ruiz, R.; Choudhary, D.; Nickel, B.; Toccoli, T.; Chang, K.C.; Mayer, A.C.; Clancy, P.; Blakely, J.M.; Headrick, R.L.; Iannotta, S.; et al. Pentacene thin film growth. Chem. Mater. 2004, 16, 4497-4508. [CrossRef]

37. Nickel, B.; Barabash, R.; Ruiz, R.; Koch, N.; Kahn, A.; Feldman, L.C.; Haglund, R.F.; Scoles, G. Dislocation arrangements in pentacene thin films. Phys. Rev. B-Condens. Matter Mater. Phys. 2004, 70, 125401. [CrossRef]

38. Kakudate, T.; Yoshimoto, N.; Saito, Y. Polymorphism in pentacene thin films on Si O2 substrate. Appl. Phys. Lett. 2007, 90, 130-133. [CrossRef] 